\section{Detection of polystyrene nanoplastics in biological tissues with a fluorescent molecular rotor probe}

\author{
François Gagné \\ Aquatic Contaminants Research \\ Division, Environment and Climate \\ Change Canada, Montreal, Quebec, \\ Canada
}

\begin{abstract}
The release of nanoplastics (NPs) from the weathering and degradation of plastics is an important environmental concern. Given their small sizes and their invasiveness in cells, methods for the detection of NPs in biological tissues are urgently needed. A simple fluorescence-based methodology for the detection of polystyrene NPs in biological tissues is proposed. The commercially available molecular rotor probe 9(dicyanovinyl)-julolidine (DCVJ) has the properties to detect changes in hydrophobicity and microviscosity and was used to detect NPs. Increasing concentrations of 50 and $100 \mathrm{~nm}$ NPs in water and in tissue extracts were mixed with the DCVJ probe and the emission spectra determined between $480-800 \mathrm{~nm}$ at $450 \mathrm{~nm}$ excitation. The data revealed that NPs induces a second emission peak at $620 \mathrm{~nm}$ that differed from the normal spectra of the biological extract at $500 \mathrm{~nm}$. A significant linear relationship was obtained for NPs of both sizes $(\mathrm{r}=0.98 ; \mathrm{P}<0.001)$ with a theoretical limit of detection of $65 \mathrm{ng} / \mathrm{mL}$. A simple and rapid microplate spectrofluorometric method for the semi-quantitative detection of polystyrene NPs in biological tissues is thus presented.
\end{abstract}

\section{Introduction}

Plastic pollution represents one of the major threats for the aquatic ecosystem. Plastic debris in the oceans spans over hundreds of square $\mathrm{km}$ thus forming very large masses coined as the $7^{\text {th }}$ continent. Hence, the continuing release of plastics in the environment is considered a major contamination problem which could threaten aquatic life. ${ }^{1}$ Although plastics are considered inert materials they will nevertheless degrade in the environment by both abiotic and biotic processes into smaller particles termed as microplastics. Microplastics are operationally defined as particles between size 1 to 5000 um. $^{2}$ A number of studies found the presence of microplastics in both coastal and freshwater sediments.,4 Microplastics were also captured by wildlife including invertebrates such as mussels and Hydra digestive systems and circulatory system which suggest that these compounds readily contaminate the aquatic biota. $^{5-7}$ Current evidence suggest that microplastics will also degrade into smaller particles in the nanoscale. ${ }^{8}$ Nanoplastics (NPs) are operationally defined as particles in the size range between $1-1000 \mathrm{~nm} .{ }^{9}$ The toxicity of NPs will be different to that of microplastics because at this scale, the nanoparticles would not only penetrated tissues but will penetrate at the subcellular levels introducing potentially unknown effects within the cell's macromolecule domain. Hence, the release of plastics in the environment could become a Pandora's box problem over time as weathering and degradation processes are proceeding which will release staggering quantities of NPs that will ultimately reach organisms in the environment. For example, Daphnia pulex exposed to $75 \mathrm{~nm}$ polystyrene NPs, the $48 \mathrm{~h}-$ median lethal concentration (LC50) was 77 $\mathrm{mg} / \mathrm{L}$ and produced adverse effects on growth, reproduction and mobility at concentration 2-3 orders lower that the lethal concentration. ${ }^{10}$ However, this concentration is not expected to be environmentally relevant but the long-term accumulation of NPs is currently unknown where they can accumulate to high levelsin tissues. In hydra exposed to concentrations of polyethylene flakes $(<400 \mu \mathrm{m})$, significant reductions in feeding rates were observed at $0.02 \mathrm{~g} / \mathrm{L}$ with some non-lethal morphological changes. ${ }^{6}$

Methods for the detection of NPs in biological tissues are therefore urgently needed to determine the occurrence of NPs in biological tissues. We hypothesize that the increasing presence of NPs in cells will increase hydrophobic interactions in the cytoplasm and membranes given the hydrophobic nature of NPs. For example, polystyrene is one of the major polymers used in the industry (coffee cups, food containers, building insulation) consists in a polymer of styrene molecule composed of benzene and propylene carbon units. Fluorescent probes that detect hydrophobic interactions are currently available which are used as microviscosity and micropolarity sensors. ${ }^{11}$ The probe 9(dicyanovinyl)-julolidine (DCVJ) is a fluorescent dye of the molecular rotor class. The fluorescence properties of DCVJ rest on its capacity to decrease its energy state by either radiation or by molecular rotation. The contribution of each state depends on the free volume of the microenvironment where hydrophobic and viscous microenvironments limit molecular rotation thereby increasing the quantum yield of fluorescence. The fluorescence quantum
Correspondence: François Gagné, Aquatic Contaminants Research Division, Environment and Climate Change Canada, Montreal, Quebec, Canada.

E-mail: francois.gagne@canada.ca

Key words: Polystyrene; Nanoplastics; Molecular rotor probe; Tissues.

Conflict of interest: The author declares no potential conflict of interest.

Funding: This work was funded by Environment and Climate Change Canada.

Received for publication: 1 March 2019.

Revision received: 10 May 2019.

Accepted for publication: 10 May 2019.

This work is licensed under a Creative Commons Attribution NonCommercial 4.0 License (CC BY-NC 4.0).

CCopyright F. Gagné, 2019

Licensee PAGEPress, Italy

Journal of Xenobiotics 2019; 9:8147

doi:10.4081/xeno.2019.8147

yield was shown to increase by a factor of 30 when the viscosity of the solvent was increased by glycerol for example. ${ }^{12}$ The probe was used to monitor changes in viscosity in low polarity environment such as membranes and liposomes. In the case of polystyrene or other NPs, the hydrophobic interaction of the probe and the plastic polymers at the surface of the nanoparticle should limit the release of energy by molecular rotation in favor of loss of energy by increased fluorescence. The purpose of this study was therefore the examine the fluorescence properties of DCVJ probe in the presence of NPs of 2 sizes (50 and 100 $\mathrm{nm})$ that could form the basis of yet undetectable transparent NPs presence in biological tissues.

\section{Materials and Methods}

Methanol, glycerol, DCVJ were purchased from Sigma chemical company (ON, Canada). Uncoated polystyrene plastic nanobeads of 100 and $50 \mathrm{~nm}$ diameter were purchased from Polyscience (USA). The tissue extracts were prepared from freshwater mussels (Elliptio complanata) as follows. Adult mussels $(89 \pm 10 \mathrm{~mm}$ shell length) were dissected on ice for the digestive gland and homogenized at $20 \%(\mathrm{w} / \mathrm{v})$ in ice-cold $50 \mathrm{mM} \mathrm{NaCl}$ containing $10 \mathrm{mM}$ Hepes-NaOH, pH 7.4, 1 mM EDTA and 1 $\mathrm{mM}$ dithiothreitol. The homogenate was decanted and centrifuged at $15,000 \times \mathrm{g}$ for 20 min at $2^{\circ} \mathrm{C}$. The resulting supernatant (S15 
fraction) were collected from the pellet and upper lipid layer and stored at $-85^{\circ} \mathrm{C}$ until analysis. NPs suspensions did not precipitate at this centrifugation speed and freezing at $-85^{\circ} \mathrm{C}$ did not produce any precipitation after thawing and centrifugation. The S15 fraction from 3 individuals were pooled for fluorescence studies. Total proteins were determined using the protein dye binding potential. ${ }^{13}$

The solid DCVJ probe was dissolved at a concentration of $1 \mathrm{mM}$ in methanol and stored in the dark at $4^{\circ} \mathrm{C}$. The DCVJ probe was diluted at $10 \mu \mathrm{M}$ in MilliQ water just before the assays. For fluorescence analysis, the NPs (50 and $100 \mathrm{~nm}$ ) and S15 were analyzed as follows. A sample volume of 50 $\mu \mathrm{L}$ of increasing concentration of NPs (final concentration: $0,0.9,1.8,2.7,3.6$ and 7.2 $\mu \mathrm{g} / \mathrm{mL})$ in water or in the presence of $\mathrm{S} 15$ fraction $(0.2 \mathrm{mg} / \mathrm{mL}$ total protein $)$ was mixed with $200 \mu \mathrm{L}$ of $10 \mu \mathrm{M}$ DCF probe for $10 \mathrm{~min}$ in dark 96-well microplates. The emission spectra was generated at $450 \mathrm{~nm}$ excitation and 480-800 nm using microplate fluorimeter (Synergy-4, Biotek, USA). To determine the influence of microviscosity on the observed emission signal, the probe $(200 \mu \mathrm{L})$ was mixed with increasing concentrations of glyrerol (50 $\mu \mathrm{l}$ sample volume) between $0.2-2 \mu \mathrm{g} / \mathrm{mL}$. Spectra scans data were imported to an Excell spreedsheet and analysed with SYSTAT software (version 13.2; USA). The theoretical limit of detection was defined as the concentration that produce a fluorescence signal corresponding 2 times the standard deviation of the DCVJ blank.

\section{Results and Discussion}

The NPs did not produce any important autofluorescence when dissolved in water in the absence of the fluorescence DCVJ probe at the wavelength used. In the presence of the tissue extract (S15), the addition of the DCVJ probe produced one major peak at $500 \mathrm{~nm}$ and a secondary peak at 620-630 nm (Figure 1). When NPs were added to the S15-DCVJ mix, an important increase was observed at $620 \mathrm{~nm}$ (Figure $1 \mathrm{~A}$ and $\mathrm{B}$ for 50 and $100 \mathrm{~nm}$ NPs respectively) for all concentrations of NPs. The emission intensity was decreased at $500 \mathrm{~nm}$ for the $100 \mathrm{~nm}$ NPs while the emission intensity at $500 \mathrm{~nm}$ was increased with 50 $\mathrm{nm}$ NPs at $0.9 \mu \mathrm{g} / \mathrm{mL}$ and decreased at 3.6 $\mu \mathrm{g} / \mathrm{mL}$. The fluorescence intensity at 620 $\mathrm{nm}$ but not at $500 \mathrm{~nm}(450 \mathrm{~nm}$ excitation) was linearly correlated $(\mathrm{r}=0.98 ; \mathrm{P}<0.001)$ with the increasing concentration of NPs alone or in the presence of tissue extract (S15) (Figure 2). The increase in emission intensity was seemingly independent of the
A
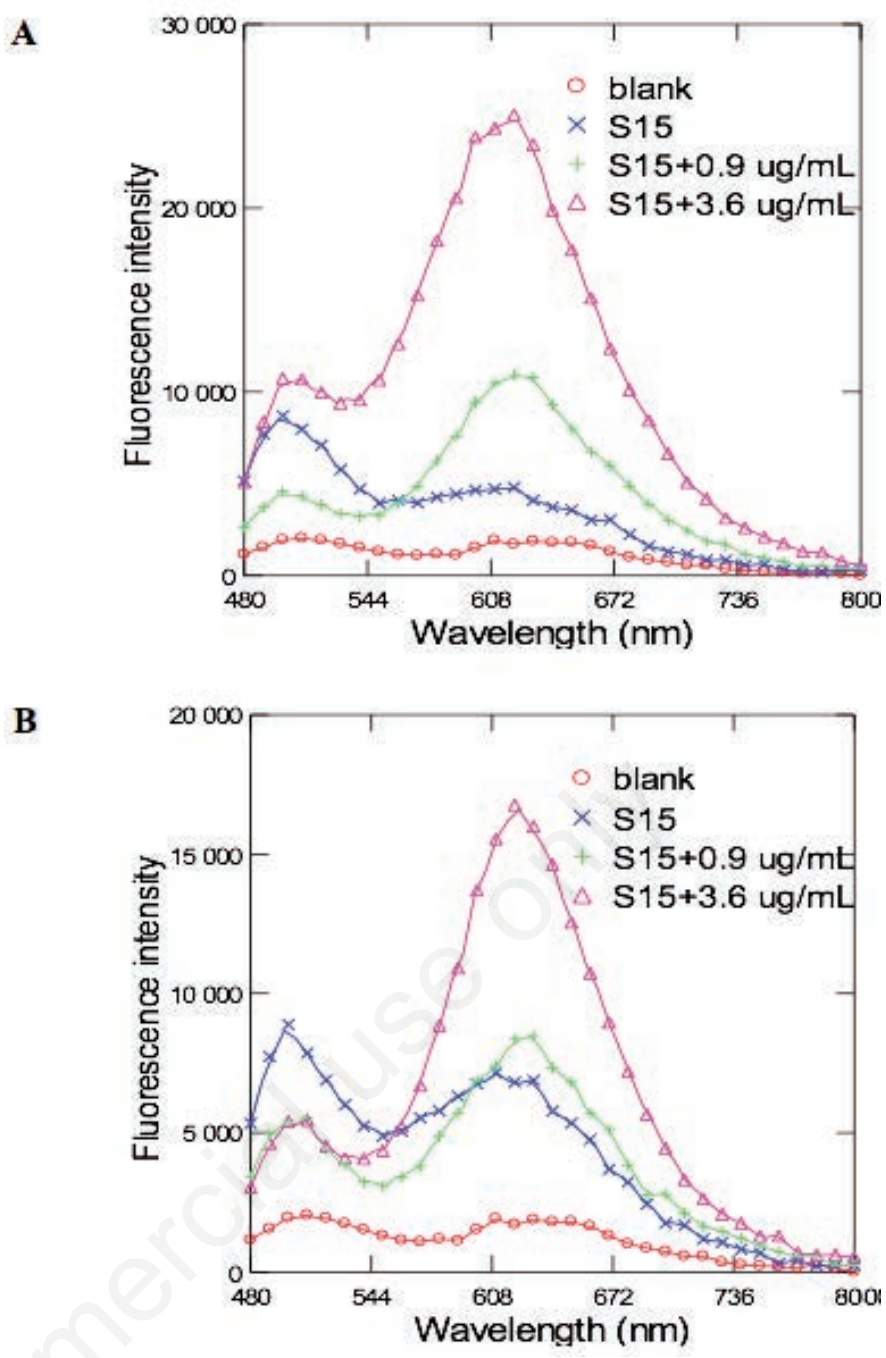

Figure 1. Emission spectra of 9-(dicyanovinyl)-julolidine (DCVJ) probe in the presence of nanoplastics (NPs). Fluorescence emission spectra of DCVJ probe in the presence of polystyrene NP of $50 \mathrm{~nm}$ (A) and $100 \mathrm{~nm}$ (B). Excitation was at $450 \mathrm{~nm}$ and emission spectra obtained between $480-800 \mathrm{~nm}$. The blank consisted of the DCVJ probe in water.

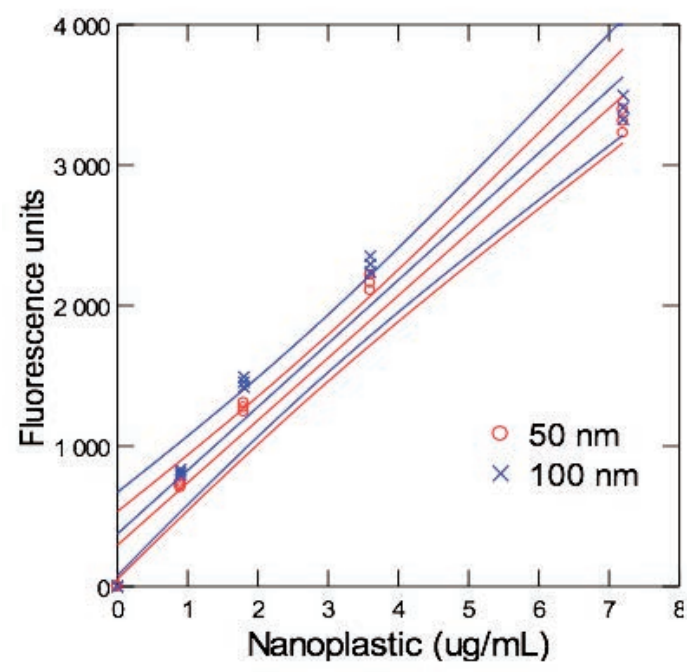

Figure 2. Change in fluorescence with additions of 50 and $100 \mathrm{~nm}$ nanoplastics (NPs) in biological tissues. Increasing concentrations of NPs were added to tissue extracts (S15 fraction) and fluorescence determined at $450 \mathrm{~nm}$ excitation and emission at $620 \mathrm{~nm}$. The theoretical detection limit was $65 \mathrm{ng} / \mathrm{mL}$ for 50 and $100 \mathrm{~nm}$ NPs. The lines represent the linear regression with the $95 \%$ confidence intervals. 
Table 1. Influence of glycerol concentration on the fluorescence spectra of the 9-(dicyanovinyl)-julolidine probe.

\begin{tabular}{lcc}
$\begin{array}{l}\text { Glycerol } \\
\text { (ug/mL) }\end{array}$ & $\begin{array}{c}\text { Emission } 500 \mathrm{~nm} \\
\text { (Fluorescence units sample-blank) }\end{array}$ & $\begin{array}{c}\text { Emission } 620 \mathrm{~nm} \\
\text { (Fluorescence units sample-blank) }\end{array}$ \\
0 & 0 & 0 \\
0.6 & $247 \pm 12$ & $150 \pm 10$ \\
\hline 1 & $582 \pm 25$ & $190 \pm 15$ \\
1.4 & $897 \pm 40$ & $201 \pm 10$ \\
1.8 & $1041 \pm 50$ & $536 \pm 25$ \\
\hline
\end{tabular}

NPs size as they displayed similar (non-significant, $\mathrm{P}>0.05$ ) slopes. The theoretical limit of detection of NPs was estimated at $65 \mathrm{ng} / \mathrm{mL}$ for both 50 and $100 \mathrm{~nm}$ polystyrene NPs. These concentrations appear somewhat elevated for the environment but not for laboratory exposures. However, it is not known if NPs will persist in the environment, accumulate in organisms and the capacity of organisms to eliminate NPs. We exposed Hydra to these same NPs and found that NPs tissue concentration in Hydra did not decrease after $24 \mathrm{~h}$ in clean media (unpublished data). Moreover, fluorescence intensity followed no clear pattern at $500 \mathrm{~nm}$ emission. Given that the DCVJ probe could measure changes in microviscosity, ${ }^{11}$ we examined whether changes in viscosity by glycerol could change the fluorescent values at $620 \mathrm{~nm}$ in addition to the normal changes observed at $500 \mathrm{~nm}$ (Table 1). The data revealed that although glycerol concentrations readily increased fluorescence at $500 \mathrm{~nm}$ and linear increase in fluorescence intensity, albeit at lower intensity, was also observed at 620 $\mathrm{nm}$. This suggests that the fluorescence at $620 \mathrm{~nm}$ is also influenced by viscosity changes in the media as well.

The introduction of NPs to the DCVJ probe leads to an increase in fluorescence and to a bathochromic shift of the emission maximum from 500 to $650 \mathrm{~nm}$ emission intensity. The close association of the DCVJ probe with the polystyrene surface of the NPs readily increased the fluorescence value at $620 \mathrm{~nm}$ in a concentration dependent manner. This is keeping with the molecular rotor definition of the probe where the loss of rotation of molecule at the hydrophobic environment of the NPs surface favors loss of energy by emission processes $^{12}$. This property is not lost in the presence of tissue extracts (S15 fraction) which makes this molecular rotor probe useful for the detection of NPs in biological tissues. Indeed, a linear relationship between emission at $620 \mathrm{~nm}$ and NPs con- centration of 50 and $100 \mathrm{~nm}$ diameter was obtained with a theoretical limit of detection of $65 \mathrm{ng} / \mathrm{mL}$. The usual fluorescence signal at $500 \mathrm{~nm}$ was not quantitative with NPs concentration, which suggests that the DCVJ state at the surface of the NPs involves changes at lower energy. A less compact environment permits for more kinetic rotor movement leading to lower energy dissipation in fluorescence (higher wavelength) than the environment of membrane phospholipids or liposomes. However, the fluorescence intensity at 620 $\mathrm{nm}$ of the NPs was higher in the presence of S15 (higher quantum yield), which suggests that phospholipids or other less polar compounds in the S15 fraction also interact at the surface of the NPs. This suggests that the corona of NPs in tissue extracts involves phospholipids or other hydrophobic molecules from which the molecular rotor within the corona of the NPs produce a characteristic fluorescence at $620 \mathrm{~nm}$. The nature of these interactions are similar to those observed with increased viscosity with glycerol additions given that glycerol both increased fluorescence at $500 \mathrm{~nm}$ and $620 \mathrm{~nm}$ albeit the fluorescence intensity changes were higher at $500 \mathrm{~nm}$ than at 620 $\mathrm{nm}$

\section{Conclusions}

A simple method for the detection and quantitation of polystyrene NPs in biological tissues is proposed based on the use of fluorescent molecular rotors DCVJ probe.

\section{References}

1. UNEP. UNEP Year Book 2011: Emerging issues in our global environment. 2011. Available from: http://wedocs.unep.org/handle/20.500.1 $1822 / 8276$
2. Lambert S, Wagner M. Characterisation of nanoplastics during the degradation of polystyrene. Chemosphere 2016;145: 265-8.

3. Browne MA, Crump P, Niven SJ, Teuten E, Tonkin A, Galloway T, et al. Accumulation of microplastic on shorelines worldwide: sources and sinks. Environ Sci Technol 2011;45:9175-9.

4. Castaneda RA, Avlijas S, Simard MA, Ricciardi A. Microplastic pollution in St. Lawrence river sediments. Can J Fish Aquat Sci 2014;71:1767-71.

5. Browne MA, Dissanayake A, Galloway TS, Lowe DM, Thompson RC. Ingested microscopic plastic translocates to the circulatory system of the mussel, Mytilus edulis (L.). Environ Sci Technol 2008;42:5026-31.

6. Murphy F, Quinn B. The effects of microplastic on freshwater Hydra attenuata feeding, morphology \& reproduction. Environ Poll 2018;234:487-94.

7. Rist S, Baun A, Hartmann NB. Ingestion of micro- and nanoplastics in Daphnia magna. Quantification of body burdens and assessment of feeding rates and reproduction Environ Poll 2017;228:398-407.

8. Mattsson K, Hansson LA, Cedervall T. Nano-plastics in the aquatic environment. Environ Sci Process Impacts 2015;17:1712-21.

9. Gigault J, Halle A, Beaudrimont M, Pascal P-Y, Gauffre F, Phi T-L, et al. Current opinion: what is a nanoplastic? Environm Poll 2018;235:1030-4.

10. Liu Z, Yu P, Cai M, Wu D, Zhang M, Huang Y, et al. Polystyrene nanoplastic exposure induces immobilization, reproduction, and stress defense in the freshwater cladoceran Daphnia pulex. Chemosphere 2019;215:74-81.

11. Haidekker MA, Brady TP, Lichlyter D, Theodorakis EA. Effects of solvent polarity and solvent viscosity on the fluorescent properties of molecular rotors and related probe. Bioorganic Chem 2005;33:415-25.

12. Kung E, Reed JK. Microviscosity measurements of phospholipid bilayers using fluorescent dyes that undergo torsional relaxation. Biochem 1986;25: 6114-21.

13. Bradford MM. A rapid and sensitive method for the quantitation of microgram quantities of protein utilizing the principle of protein-dye binding. Anal Biochem 1976;72:248-54. 